\title{
Archéopages
}

Archéopages

Archéologie et société

Hors-série 1 | 2008

Construction $^{s}$ de l'archéologie

\section{Nîmes : vingt ans d'aménagements et de découvertes}

Jean-Yves Breuil et Pierre Séjalon

\section{(2) OpenEdition}

\section{Journals}

Édition électronique

URL : https://journals.openedition.org/archeopages/836

DOI : 10.4000/archeopages.836

ISSN : 2269-9872

Éditeur

INRAP - Institut national de recherches archéologiques préventives

Édition imprimée

Date de publication : 1 février 2008

Pagination : 21-22

ISSN : 1622-8545

\section{Référence électronique}

Jean-Yves Breuil et Pierre Séjalon, « Nîmes : vingt ans d'aménagements et de découvertes »,

Archéopages [En ligne], Hors-série 1 | 2008, mis en ligne le 01 février 2008, consulté le 02 mars 2023.

URL : http://journals.openedition.org/archeopages/836; DOI : https://doi.org/10.4000/archeopages. 836 


\section{Nîmes: vingt ans d'aménagements et de découvertes}

\section{Jean-Yves Breuil}

Pierre Séjalon

Inrap, UMR 5140 "Archéologie des sociétés méditerranéennes»

$\mathrm{E}$ écho à l'ouvrage dirigé par Jean-Paul Demoule, La France archéologique, publié en 2004, nous souhaitons dresser ici un bref panorama historiographique de l'archéologie préventive à Nîmes. Si, dans les grandes lignes, l'histoire de l'archéologie préventive nîmoise rejoint celle de la pratique de l'archéologie en France, la ville se singularise néanmoins par la présence d'un patrimoine monumental antique qui, depuis la Renaissance, a toujours suscité l'intérêt des nombreux chercheurs nîmois: la tour Magne, ancienne tour de guet, le sanctuaire dynastique de la Fontaine, la porte d'Auguste, porte de l'enceinte antique, la Maison carrée, temple lié au culte impérial, ou encore l'amphithéâtre, lieu des combats de gladiateurs. Ces monuments insignes sont autant de marqueurs du paysage urbain actuel, à partir desquels s'est développée l'archéologie de sauvetage nîmoise. La mise au jour de l'histoire antique de Nîmes doit aussi beaucoup aux acteurs locaux, érudits, universitaires, conservateurs et chercheurs qui, au fil des années, ont su capitaliser et partager des connaissances, transmettre un savoir et promouvoir progressivement une archéologie exigeante et collective s'adaptant à l'aménagement croissant du territoire nîmois.

À une archéologie pratiquée aux XVIII ${ }^{\mathrm{e}}$ et XIX ${ }^{\mathrm{e}}$ siècles par des antiquaires éclairés succèdent, dès la première moitié $\mathrm{du} \mathrm{xx}^{\mathrm{e}}$ siècle, les nombreuses observations recensées par les conservateurs successifs du Musée archéologique de Nîmes, au gré des travaux de construction, de réfection de voirie ou d'installation de réseaux. Dans les années 1960 et 1970, la multiplication des projets urbains entraîne la réalisation des premières fouilles de sauvetage, militantes mais limitées en raison de conditions d'exécution difficiles; durant cette période, la recherche archéologique arrive difficilement à faire face au rythme des destructions. ${ }^{1}$

Un véritable tournant s'opère au début des années 1980, marquées par une série de grands projets d'urbanisme à l'intérieur de la ville romaine qui induisent des fouilles de sauvetage, sur une surface totale de 5000 mètres carrés (autour de la Maison carrée, sur les portes de l'enceinte augustéenne, sur l'enceinte protohistorique, au sein de l'amphithéâtre...). C'est aussi de cette période que datent l'article pionnier de Jean Benoit (1981) sur la morphologie parcellaire urbaine, les travaux de Christian Goudineau (1976) et de Michel Py (1981) sur la Nîmes préromaine et ceux dirigés par Raymond Huard (1982) sur l'histoire de Nîmes.

Quelques années plus tard, en 1987, l'aménagement de l'autoroute Nîmes-Arles entraînera les premiers travaux d'archéologie préventive dans la campagne nîmoise. Ce déplacement des investigations dans la plaine située au sud de l'agglomération permettra la mise au jour de vestiges plus anciens, premiers témoignages d'une richesse archéologique préromaine plutôt inattendue.

À partir de la fin des années 1980, le service régional de l'Archéologie de LanguedocRoussillon, en concertation étroite avec Marc Célié, alors archéologue attaché à la ville de Nîmes, met en place une politique de suivi archéologique systématique des secteurs soumis à des projets d'aménagement sur le territoire de la commune, notamment les 220 hectares de la cité romaine et la partie méridionale de la ville, la plus touchée par l'urbanisation. Cette politique a pour corollaire un rythme assez constant d'opérations, et permet peu à peu la constitution d'une équipe stable d'archéologues.

Dès 1990, s'adaptant aux territoires appréhendés par l'archéologie au sud de la ville, la recherche se porte sur l'analyse des articulations entre l'agglomération et son espace rural, depuis le premier regroupement d'habitations autour de la source de la Fontaine au vi ${ }^{\mathrm{e}}$ siècle avant notre èrejusqu'à la fin du Moyen Âge. Elle se formalise notamment à travers l'élaboration d'un programme collectif d'archéologie spatiale et de prospection-inventaire, le projet «Nîmes rurbain», présenté par le Genos (Groupe d'étude nîmois sur l'occupation des sols), coordonné par Pierre Poupet (1990).

Ce projet donnera une impulsion aux travaux sur le paléoenvironnement qui se concrétiseront à l'occasion des opérations liées au plan de protection contre les inondations de la ville de Nîmes (PPCI). C'est depuis lors un axe prioritaire des recherches nîmoises (Martin et al. 2005).

Parallèlement, durant les années 1990, des travaux universitaires et des publications livrent des synthèses importantes des connaissances archéologiques. L'étude d'Alain Veyrac (1991) sur Nîmes antique et l'eau, le volume consacré à Nîmes dans le cadre de la carte archéologique de la Gaule sous la direction de Jean-Luc Fiches et d'Alain Veyrac (1996), le travail de Martial Monteil (1999) sur Nîmes antique et sa proche campagne et la thèse soutenue en 2000 par Laurent Vidal sur l'aménagement des campagnes de la Protohistoire au Moyen Âge en Languedoc central et oriental constituent - pour ne citer qu'eux - un indiscutable cadre de référence pour la réflexion historique nîmoise.

Depuis lors, les projets d'aménagements continuent d'affecter la ville et la campagne alentour. Le domaine strictement urbain est régulièrement investi par des fouilles,

et une nouvelle politique d'aménagements extrait d'une note

non publiee,

conservateurs

sont en charge du

département du Gard,

respectivement

depuis 1990 et 1992. 
publics entraîne depuis 2005 une intensification remarquable des opérations archéologiques dans la ville antique et dans l'écusson médiéval situé autour de la cathédrale. Ces fouilles apportent de nouvelles données pour la compréhension du développement et des principales étapes d'urbanisation de la cité depuis la fin du II ${ }^{\mathrm{e}}$ siècle avant notre ère jusqu'à la fin de l'Antiquité, et sur l'organisation de la ville médiévale.

Avec l'extension de l'agglomération vers le sud, la plaine est devenue la zone la plus touchée par les programmes d'aménagements, avec la création de nouvelles zones d'activité économique, le creusement à partir de 1998 de plusieurs grands bassins de rétention d'eau (dans le cadre du PPCI) et la mise en place de nouveaux réseaux de communication.

Ces aménagements ont motivé autant d'opérations d'archéologie préventive (diagnostics et parfois fouilles) sur d'importantes superficies (elles totalisent aujourd'hui près de 250 hectares). Ils ont permis la découverte d'une masse documentaire considérable, constituée de dizaines de milliers de vestiges archéologiques de toute nature et de toutes périodes témoignant de la densité exceptionnelle de l'occupation humaine sur ce territoire. Du Paléolithique supérieur à l'époque contemporaine, toutes les grandes phases chronologiques sont représentées, avec, en particulier, des données extrêmement nombreuses pour le Néolithique, l'âge du Fer et l'Antiquité.

C'est donc la conjonction de trois facteurs une politique archéologique active depuis deux décennies, une masse considérable de données produite par l'archéologie préventive avec son enrichissement croissant et la très forte densité des occupations depuis le Néolithique sur un même secteur - qui favorise l'existence d'une véritable recherche. En 1999, à la suite du programme «Nîmes rurbain», un projet collectif de recherche $(\mathrm{PCR})$ centré sur le territoire nîmois voit le jour. Ce $P_{C R}$, qui rassemble aujourd'hui plus de quarante chercheurs, s'articule selon trois axes transversaux (protocoles et stratégies; paléoenvironnement; documentation, cartographie et système d'information géographique) et cinq axes chronologiques: Préhistoire récente (Breuil et al. 2004), Protohistoire (Sauvage 1996, Breuil, Séjalon 2007), Antiquité (Vidal et al. 1996, Bel et al. 2005), Moyen Âge et époque moderne. À partir d'actions individuelles ou collectives, ce programme tente de prendre en compte l'important volume des données disponibles dans une approche résolument diachronique, et propose une étude de l'occupation humaine du Néolithique à l'époque moderne sur un territoire d'environ $100 \mathrm{~km}^{2}$. Les premiers résultats de ces travaux renouvellent en profondeur la connaissance historique du territoire nîmois, témoignant notamment d'une forte anthropisation dès le Néolithique et d'un impact durable sur le paysage nîmois.
AmandryM., Christolm., Fiches J.-L. (dir.), VeyracA. (dir.), ManniezY., Monteil M., SauvageL., VidalL. 1996: Carte archéologique de la Gaule, Nîmes (30/1), Paris, Académie des Inscriptions et Belles-Lettres.

Bel V., Breuil J.-Y., Monteil M., Pomarèdes H. avec Vidal L. (coll.) et SAUVAGE L. (coll.) 2005: «Réflexions sur une ville et sa proche campagne dans l'Antiquité: le cas de Nîmes (Gard)», in A. Bouet et F. Verdin (éd.) Territoires et paysages de l'âge du Fer au Moyen Âge. Mélanges offerts à Philippe Leveau. Bordeaux: Ausonius Éditions, p.19-44.

BENOIT J. 1981 : « Nîmes: études sur l’urbanisme antique. Problème de méthode et résultats. » Bulletin de l'École Antique de Nîmes, nouv. série, 16, 1981, p.69-9o.

Breuil J.-Y., Escallon G., Georjon C., Gutherz X., Jallot L., LANCELOT S., LANDiER G., Léa V. 2004: «Le territoire nîmois au Néolithique. Premier bilan du groupe Néolithique au sein du PCR «Espace rural et occupation du sol de la région nîmoise de la Préhistoire récente à l'Époque moderne» », in Gascó J., Gutherz X. et de Labriffe P.-A. dir. Temps et espaces culturels. $D u 6^{e}$ au $2^{e}$ millénaire en France du Sud. Actes des quatrièmes Rencontres méridionales de Préhistoire récente. Nîmes 28 et 29 octobre 200o. Monographies d'Archéologie Méditerranéenne, 15, Lattes, p. 243-262.

BREUIL J.-Y., SÉJALON P. 2007: «Nouvelles données sur l'occupation de la fin du VI $\mathrm{e}^{\mathrm{e}} \mathrm{s}$. au $\mathrm{I}^{\mathrm{er}} \mathrm{S}$. av. notre ère dans la plaine du Vistre (Nîmes, Gard)", in L'Exploitation agricole dans son environnement à la fin de l'âge du Fer. Nouvelles approches méthodologiques, actes de la table ronde des 18 et 19 novembre 2004 coorganisée par l'EHEss de Toulouse et l'Archéosite de Saint-Julien, Toulouse.

Goudineau C. 1976: «Le statut de Nîmes et les Volques Arécomiques», Revue archéologique de Narbonnaise, 9, p.105-114.

HuARd R. (dir.) 1982: Histoire de Nîmes, Aix-en-Provence, Édisud.

Martin S., Magnin F., Chevillot P. 2005: «Mise en évidence des discontinuités spatiales et temporelles dans l'anthropisation de la plaine de la Vistrenque à Nîmes (gard) durant l'Holocène. Apport de l'analyse malacologique», Quaternaire, 16, (4), p.339-353.

MonteIL M. 1999: Nîmes antique et sa proche campagne. Étude de topographie urbaine et périurbaine (fin $V I^{e}$ av. notre ère $V I^{e}$ s. ap.J.-C.). Lattes, UMR 154 (Monographies d'archéologie méditerranéenne 3).

Poupet P., CÉLIÉ M. 1990: «Nîmes, la ville et ses campagnes. L'espace rural et ses articulations avec l'agglomération, de l'oppidum indigène à la ville moderne», Projet d'archéologie spatiale/ prospectioninventaire présenté par le GENos, multigraphié, Archives du Service régional de l'Archéologie.

Py M. 1981: Recherches sur Nîmes préromaine. Habitats et sépultures, XLI ${ }^{\mathrm{e}}$ suppl. à Gallia, Paris, Éd. du CNRS.

SAUVAGE L. 1996: «Existe-t-il une ferme indigène dans le Midi de la France? », in D. Bayard, J.-L. Collart dir. De la ferme indigène à la villa romaine. La romanisation des campagnes de la Gaule. Actes du deuxième colloque de l'association AgER, Amiens (Somme) du 23 au 25 septembre 1993, Revue archéologique de Picardie, $\mathrm{n}^{\circ}$ spécial, 11, p. 287-292.

VEYRAC A. 1991: Nîmes antique et l'eau. Les aménagements hydrauliques du forum, mémoire de DEA, Université de Provence, Aix-enProvence.

Vidal L., Pomarèdes H. (coll.), Sauvage L. (coll.) 1996: «Traces matérielles de la mise en valeur et de l'aménagement des campagnes aux portes de Nîmes: les parcellaires antiques de la plaine du Vistre», in G. Chouquer (dir.) Les formes du paysage. Tome 2. Archéologie des parcellaires. Actes du colloque d'Orléans (1996), p.57-66.

\section{Ô Bonne Mère...}

Jean Guilaine

Collège de France

$\mathrm{L}$ 'ambition légitime du préhistorien ou du protohistorien de dépasser le champ des analyses matérielles pour tenter de pénétrer celui des organisations sociales, des rapports de pouvoir, des croyances et des pratiques «religieuses» a donné lieu à une littérature abondante. Les difficultés que rencontre l'archéologue pour modéliser à partir de ses propres vestiges lui fait souvent utiliser et adopter sans discussion des constructions anthropologiques ou historiques, elles-mêmes spéculatives. On prendra ici l'exemple de la «déesse» néolithique; un concept qui, sous des formulations et des contenus divers, 